\title{
The Effect of Vasopressors on Perfusion of Gastric Graft after Esophagectomy
}

\author{
Marc Buise • Jasper van Bommel • Diederik Gommers
}

Received: 9 October 2008 / Accepted: 18 February 2009 /Published online: 10 March 2009

(C) The Author(s) 2009. This article is published with open access at Springerlink.com

Dear editor,

We read with interest the article on gastric graft perfusion by Theodorou and co-workers. ${ }^{1}$ The article describes the negative effect of norepinefrin in gastric graft microcirculation. Gastric microvascular blood flow following esophagectomy is a difficult area for research at which we recently tried to contribute and we encourage every research in this specific field. ${ }^{2,3}$

However, we have some remarks on this study. First, the use of a hemorrhage model is not a good analog of the clinical situation. The use of vasopressors in case of hemorrhage will affect microcirculation. Hypotension during surgery and especially the hemodynamic effect of epidural analgesia, as mentioned in the conclusion, have other physiological mechanisms. Recently, the positive effect of epinephrine on gastric tube perfusion, in combination with epidural analgesia has been described. ${ }^{4}$ Second, in humans, the gastric tube is fashioned along the greater curvature of the stomach, and the blood supply is mainly based on the right gastricepiploic artery. In the model used, blood supply of the gastric graft was also based on the right gastroepiploic artery. In pigs, however, the main characteristic of vascular anatomy was a dominant left gastroepiploic artery, sometimes combined with well-defined short gastric arteries. ${ }^{5}$ Third, fluid management is of great importance in such a study, but no additional information is given. We wonder why blood pressure was so low at the end of the hemorrhage; in a pig of $30 \mathrm{~kg}$, the loss of $200 \mathrm{ml}$ blood is normally not accompanied by a decrease in pressure. We

\footnotetext{
M. Buise ( $\square)$

Catharina Hospital Eindhoven,

Eindhoven, The Netherlands

e-mail: marc.buise@cze.nl

J. van Bommel • D. Gommers

Erasmus MC,

Rotterdam, The Netherlands
}

miss the information of central venous pressure and cardiac output. Animal number 5 is not recovering from the shock, and blood pressure is extremely low during steps 3 and 4. Is this animal still representative for the study? According to the protocol, the blood pressure should be increased from 80 to $90 \mathrm{~mm} \mathrm{Hg}$. Figure 1, in their article, shows this goal was never reached. Is this perhaps an effect of hypovolemia?

Finally, in our opinion, the use of paired $t$ test in this study design is not appropriate. Analysis of variance would be more correct for repeated measurements.

Yours sincerely,

Open Access This article is distributed under the terms of the Creative Commons Attribution Noncommercial License which permits any noncommercial use, distribution, and reproduction in any medium, provided the original author(s) and source are credited.

\section{References}

1. Theodourou D, Drimousis PG, larantzakis A, Papalois A, Toutouzas KG, Katsagari S. The effect of vasopressors on perfusion of gastric graft after esophagectomy. An experimental study. J Gastrointest Surg 2008;12:1497-1501. doi:10.1007/ s11605-008-0575-y.

2. Buise MP, Ince C, Tilanus HW, Klein J, Gommers D, van Bommel J. The effect of nitroglycerine on microvascular perfusion and oxygenation during gastric tube reconstruction. Anesth Analg 2005;100:1107-1111. doi:10.1213/01.ANE.0000147665.60613.CA.

3. Buise MP, van Bommel J, Jahn A, Tran K, Tilanus HW, Gommers D. Intravenous nitroglycerin does not preserve gastric microcirculation during gastric tube reconstruction: a randomized controlled trial. Crit Care 2006;10(5):R131. doi:10.1186/cc5043.

4. Al- Rawi O, Pennefather SH, Page RD, Dave I, Russel GN. The effect of thoracic epidural bupivacaine and an intravenous adrenalin infusion on gastric tube blood flow during esophagectomy. Anesth Analg 2008;106:884-887.

5. Schroder W, Beckurts KTE, Stahler D, Stutzer H, Fischer JH, Holscher AH. Microcirculatory changes associated with gastric tube formation in the pig. Eur Surg Res 2002;34:411-417. doi:10.1159/000065709. 